\title{
The combination of paclitaxel and carboplatin as second-line chemotherapy can be a preferred regimen for patients with urothelial carcinoma after the failure of gemcitabine and cisplatin chemotherapy
}

\author{
NOBUKI FURUBAYASHI ${ }^{1}$, TAKAHITO NEGISHI ${ }^{1}$, TAKUYA YAMASHITA ${ }^{1}$, SHUHEI KUSANO ${ }^{1}$, \\ KENICHI TAGUCHI ${ }^{2}$, MOTOTSUGU SHIMOKAWA ${ }^{3}$ and MOTONOBU NAKAMURA ${ }^{1}$ \\ Departments of ${ }^{1}$ Urology and ${ }^{2}$ Pathology; ${ }^{3}$ Institute for Clinical Research, \\ National Kyushu Cancer Center, Fukuoka, Fukuoka 811-1395, Japan
}

Received May 18, 2017; Accepted July 21, 2017

DOI: $10.3892 / \mathrm{mco} .2017 .1452$

\begin{abstract}
There is no established standard second-line chemotherapy after the failure of the first-line cisplatin-based chemotherapy for patients with advanced or metastatic urothelial carcinoma. With regards to second-line chemotherapy, methotrexate, vinblastine, doxorubicin and cisplatin (MVAC) was used from July 2009 onwards, and paclitaxel and carboplatin (TC) was introduced in April 2014 at the National Kyushu Cancer Center. The present study aimed to assess the prognostic factors for overall survival (OS) in second-line treatment that included best supportive care (BSC), and the tolerability and efficacy of TC chemotherapy. In total, 52 patients who were confirmed to have disease progression with first-line gemcitabine and cisplatin (GC) between June 2009 and November 2016 were enrolled in the current study. In addition, 28 patients selected BSC as second-line treatment, while 24 patients received second-line chemotherapy (MVAC, $n=8 ;$ TC, $n=16$ ). The median OS for BSC, MVAC and TC was $2.8,5.4$, and 12.7 months, respectively. The difference between BSC and MVAC was not statistically significant $(\mathrm{P}=0.596)$. However, the difference between BSC and TC was statistically significant after Bonferroni correction $(\mathrm{P}=0.002)$. Multivariate analyses revealed that anemia [hazard ratio (HR), 7.047; 95\% confidence interval $(\mathrm{CI}), 1.553-35.636 ; \mathrm{P}=0.011]$, the presence of visceral metastasis (HR, 4.174; 95\% CI, 1.506-13.429; $\mathrm{P}=0.005$ ) and second-line treatment (TC HR, 0.296 ; 95\% CI, 0.124-0.636; $\mathrm{P}=0.003$ ) were independent prognostic factors. TC achieved an $18.7 \%$ overall response rate and a $56.2 \%$ disease control rate. Myelosuppression was the
\end{abstract}

Correspondence to: Dr Nobuki Furubayashi, Department of Urology, National Kyushu Cancer Center, Notame 3-1-1, Minami-ku, Fukuoka, Fukuoka 811-1395, Japan

E-mail: furubayashi.n@nk-cc.go.jp

Key words: urothelial carcinoma, gemcitabine and cisplatin, paclitaxel and carboplatin, second-line chemotherapy, overall survival most common grade $\geq 3$ toxicity, but no treatment-associated mortalities occurred during the study period. TC was associated with favorable benefits and safety, and may be considered a preferred regimen after the failure of GC.

\section{Introduction}

Urothelial carcinoma (UC) is one of the most common urological malignancies worldwide. Approximately $30 \%$ of UC patients initially present with muscle invasion and metastasis (1). In addition, despite the performance of radical surgery as a local therapy for patients with muscle invasion, more than one-third of these patients ultimately develop metastatic disease (2).

Cisplatin-based systemic chemotherapy is the gold standard approach for patients with advanced or metastatic UC. Combined chemotherapy with methotrexate, vinblastine, doxorubicin and cisplatin (MVAC), which was developed in 1985, is an effective and frequently used modality for these life-threatening diseases (3-7). Recently, combined chemotherapy with gemcitabine and cisplatin (GC) has become another standard treatment for advanced UC, since GC therapy showed equivalent efficacy and less toxicity in comparison to MVAC in a randomized phase 3 trial (8). However, no standard second-line chemotherapy regimens have been established for cases in which a first-line cisplatin-based chemotherapy (such as MVAC or GC) fails. The administration of vinflunine in combination with the best supportive care (BSC) as a second-line chemotherapy after the failure of cisplatin-based regimens was associated with a 2.5-month increase in survival in comparison to patients who received BSC alone in a phase 3 trial (9). However, vinflunine has only been approved in Europe.

Various single agents and combinations of agents have been reported as second-line chemotherapy regimens. Among these, combined chemotherapy with paclitaxel and carboplatin (TC) has been shown to have promising therapeutic activity against cisplatin-refractory UC (10-12). However, few reports have assessed the tolerability and efficacy of TC therapy as 
a second-line regimen for $\mathrm{UC}$ showing resistance to $\mathrm{GC}$ as a first-line chemotherapy regimen. Our institution has used MVAC as a second-line chemotherapy regimen for patients with advanced urothelial carcinoma after the failure of first-line GC since July 2009 and has used TC as second-line chemotherapy since April 2014. In this study, we retrospectively assessed the prognostic factors for overall survival (OS) in patients who received second-line treatment that included BSC and investigated the tolerability and efficacy of TC therapy.

\section{Patients and methods}

The data of 52 patients who received BSC or second-line chemotherapy with MVAC or TC after the failure of first-line chemotherapy with GC at our institution between June 2009 and November 2016 were retrospectively evaluated. UC was histopathologically diagnosed and disease progression during first-line chemotherapy with GC was radiologically confirmed. Twenty-eight patients selected BSC and 24 received second-line chemotherapy (MVAC, $n=8$; TC, $n=16$ ). Patients who received second-line chemotherapy were required to have an Eastern Cooperative Oncology Group (ECOG) performance status (PS) of $\leq 2$ and an adequate organ function, (defined by granulocyte count $\geq 1,500 / \mathrm{mm}^{3}$, platelet count $\geq 100,000 / \mathrm{mm}^{3}$, serum total bilirubin $<1.5 \mathrm{mg} / \mathrm{dl}$, serum transaminase activity $<3$ times that of normal and serum creatinine $<2$ times the normal level).

In the MVAC regimen, methotrexate $\left(30 \mathrm{mg} / \mathrm{m}^{2}\right)$ was administered intravenously on days 1, 15 and 22; vinblastine $\left(3.0 \mathrm{mg} / \mathrm{m}^{2}\right)$ was administered intravenously on days 2,15 and 22 ; and doxorubicin $\left(30 \mathrm{mg} / \mathrm{m}^{2}\right)$ and cisplatin $\left(70 \mathrm{mg} / \mathrm{m}^{2}\right)$ were administered intravenously on day 2 . The cycle was basically repeated every 28 days. In the TC regimen, paclitaxel $\left(175 \mathrm{mg} / \mathrm{m}^{2}\right)$ and carboplatin (area under the curve: 5) were administered by intravenous infusion on day 1 . The cycle was repeated every 21 days. The two second-line regimens were repeated until disease progression or unacceptable adverse events occurred. Tumor measurements were generally performed by computed tomography before and after every 2-3 cycles of the second-line chemotherapy. Decisions regarding adverse events were made based on the Common Terminology Criteria for Adverse Events, version 4.0 (13). The tumor response was evaluated as the best response according to the Response Evaluation Criteria In Solid Tumors, version 1.1 (14).

All of the patients provided their written informed consent to participate in this study, and the study protocol was approved by the Ethics Committee of the Kyushu Cancer Center (Fukuoka, Japan).

Statistical analysis. The statistical analyses were carried out using the JMP ${ }^{\circledR}$ Pro, version 12.2.0 software package (SAS Institute, Inc., Cary, NC, USA). OS was calculated from the day that BSC was selected or the day on which chemotherapy was started until the date of the last follow-up examination or death from any cause. The OS were evaluated using the Kaplan-Meier method, and the log-rank test (Bonferroni correction procedure) was used to determine differences between the second-line treatment groups. The significance of associations between the clinical parameters and OS was assessed using the Cox proportional hazards regression model.
Table I. Patient characteristics.

Characteristic $(\mathrm{n}=52)$

No. of patients

Gender

Male

Female

Age, years

Median (range)

$70(50-86)$

ECOG PS

0

1

21

$\geq 2$

Anemia (male $<13.5$, female $<11.0$ )

Yes

No

CRP

$<0.3$

$\geq 0.3$

Albumin

$\geq 4.0$

12

$<4.0$

NLR

Median (range)

$3.0(0.8-14.9)$

Primary tumor site

Bladder

Upper urinary tract

22

Bladder + upper urinary tract

6

Surgical treatment for the primary tumor

Cystectomy

Cystectomy + nephroureterectomy

2

Nephroureterectomy

Transurethral resection

Visceral metastasis

Negative

12

Positive

Second-line therapy

BSC

TC chemotherapy

16

MVAC chemotherapy

ECOG PS, Eastern Cooperative Oncology Group Performance, Status; CRP, C-reactive protein; NLR, neutrophil/lymphocyte ratio; BSC, best supportive care; TC, paclitaxel and carboplatin; MVAC, methotrexate, vinblastine, doxorubicin and cisplatin.

$\mathrm{P}<0.05$ was considered to indicate a statistically significant difference.

\section{Results}

Patient characteristics. The clinical characteristics of the 52 (male, $\mathrm{n}=40$; female, $\mathrm{n}=12$; median age, 70 years; range, 50-86 years) patients are listed in Table I. All the patients 
Table II. The univariate and multivariate analyses of the factors associated with overall survival in patients receiving second-line treatment.

\begin{tabular}{|c|c|c|c|c|}
\hline Variable & $\begin{array}{c}\text { Univariate } \\
\mathrm{HR}(95 \% \mathrm{CI})\end{array}$ & P-value & $\begin{array}{l}\text { Multivariate } \\
\text { HR }(95 \% \text { CI })\end{array}$ & P-value \\
\hline \multicolumn{5}{|l|}{ Age } \\
\hline$<70$ & 1 & & & \\
\hline$\geq 70$ & $0.824(0.429-1.556)$ & 0.552 & & \\
\hline \multicolumn{5}{|l|}{ Sex } \\
\hline Male & 1 & & & \\
\hline Female & $0.942(0.421-1.903)$ & 0.875 & & \\
\hline \multicolumn{5}{|l|}{ Histology } \\
\hline Pure UC & 1 & & & \\
\hline Mixed UC & $0.613(0.282-1.243)$ & 0.180 & & \\
\hline \multicolumn{5}{|l|}{ ECOG PS } \\
\hline 0 & 1 & & & \\
\hline 1 & $4.146(1.529-14.462)$ & 0.004 & & \\
\hline$\geq 2$ & $5.946(2.158-21.007)$ & $<0.001$ & & \\
\hline \multicolumn{5}{|c|}{$\begin{array}{l}\text { Anemia (male }<13.5 \text {, } \\
\text { female }<11.0 \text { ) }\end{array}$} \\
\hline Negative & 1 & & 1 & \\
\hline Positive & $2.248(0.953-6.604)$ & 0.066 & $7.047(1.553-35.636)$ & 0.011 \\
\hline \multicolumn{5}{|l|}{ NLR } \\
\hline$<3.0$ & 1 & & & \\
\hline$\geq 3.0$ & $2.010(1.055-3.903)$ & 0.034 & & \\
\hline \multicolumn{5}{|l|}{ Albumin } \\
\hline$\geq 4.0$ & 1 & & & \\
\hline$<4.0$ & $2.963(1.386-7.111)$ & 0.004 & & \\
\hline \multicolumn{5}{|l|}{ CRP } \\
\hline$<0.3$ & 1 & & & \\
\hline$\geq 0.3$ & $3.323(1.319-11.169)$ & 0.008 & & \\
\hline \multicolumn{5}{|c|}{ Best response to GC therapy } \\
\hline $\mathrm{PD}$ & 1 & & & \\
\hline $\mathrm{SD}$ & $0.712(0.319-1.579)$ & 0.401 & & \\
\hline $\mathrm{CR}+\mathrm{PR}$ & $0.785(0.369-1.686)$ & 0.528 & & \\
\hline \multicolumn{5}{|c|}{ Visceral metastases } \\
\hline Negative & 1 & & 1 & \\
\hline Positive & $2.289(1.062-5.699)$ & 0.034 & $4.174(1.506-13.429)$ & 0.005 \\
\hline \multicolumn{5}{|c|}{ Second-line treatmnet } \\
\hline BSC & 1 & & 1 & \\
\hline MVAC & $0.734(0.289-1.639)$ & 0.467 & $0.337(0.093-1.181)$ & 0.089 \\
\hline $\mathrm{TC}$ & $0.296(0.124-0.636)$ & 0.001 & $0.202(0.065-0.588)$ & 0.003 \\
\hline
\end{tabular}

UC, Urothlial carcinoma; ECOG PS, Eastern Cooperative Oncology Group Performance Status; NLR, neutrophil/lymphocyte ratio; CRP, C-reactive protein; GC, gemcitabine and cisplatin; BSC, best supportive care; TC, paclitaxel and carboplatin; MVAC, methotrexate; vinblastine; doxorubicin and cisplatin.

received $\mathrm{GC}$ as the first-line chemotherapy for urothelial carcinoma, and selected BSC or second-line chemotherapy after the failure of GC chemotherapy. Twenty-four patients had bladder UC, 22 patients had upper urinary tract UC and 6 patients had both types of UC. Forty patients (76.9\%) had visceral metastasis. With regard to the second-line treatments,
28 patients $(53.8 \%)$ selected BSC and 24 patients $(46.2 \%)$ received second-line chemotherapy (MVAC, $n=8 ; T C, n=16$ ).

OS according to the second-line treatments. The OS according to the second-line treatment is shown in Fig. 1. The median OS for BSC was 2.8 months [95\% confidence interval (CI), 1.8-4.9 


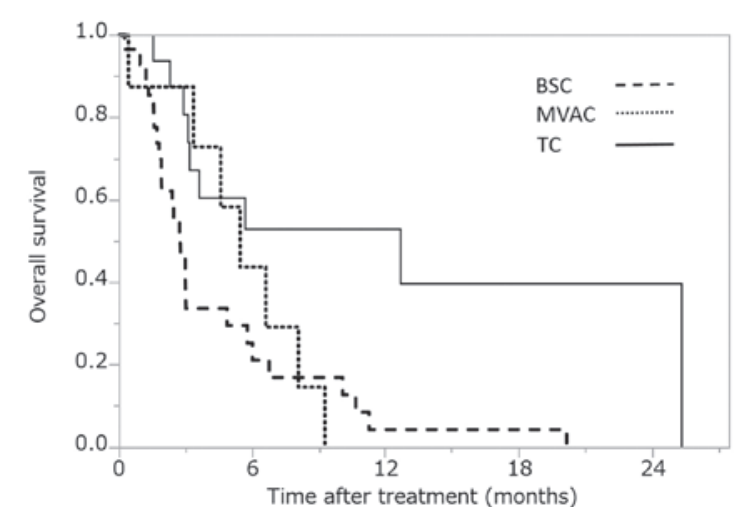

Figure 1. Overall survival according to the second-line treatment.

months; the median OS for MVAC was 5.4 months $(95 \% \mathrm{CI}$, 0.4-8.1 months], and the median OS for TC was 12.7 months (95\% CI, 3.1-25.4 months). The difference between BSC and MVAC (according to the log-rank test) was not statistically significant $(\mathrm{P}=0.596)$. However, the difference between BSC and TC was statistically significant after Bonferroni correction $(\mathrm{P}=0.002)$.

Univariate and multivariate analyses of the associations between various factors and the $O S$ after the failure of $G C$ chemotherapy. To identify the prognostic factors associated with OS after the failure of GC chemotherapy, we performed univariate and multivariate analyses using the Cox proportional hazards model (Table II). Univariate analyses for various factors revealed that prior nephrectomy, ECOG-PS, the neutrophil/lymphocyte ratio (NLR), albumin, C-reactive protein (CRP), visceral metastasis and second-line treatment were prognostic variables. The multivariate analyses revealed that anemia (male <13.5; female <11.0) (HR, 7.047, $95 \% \mathrm{CI}=1.553-35.636, \mathrm{P}=0.011)$, the presence of visceral metastasis (HR 4.174, 95\% $\mathrm{CI}=1.506-13.429, \mathrm{P}=0.005)$ and second-line treatment (TC: HR 0.296, 95\% CI=0.124-0.636, $\mathrm{P}=0.003$ ) were independent prognostic factors.

The response analysis and the toxicities in patients who received TC as a second-line chemotherapy regimen. The objective tumor responses are shown in Table III. Among the 16 patients who received TC as a second-line chemotherapy regimen, a complete response (CR) was confirmed in 1 patient $(6.2 \%)$, while 2 patients $(12.5 \%)$ showed a partial response (PR), with an overall response rate of $18.7 \%$. The disease control rate (defined by the achievement of CR, PR or stable disease [SD]), was $56.2 \%$.

Table IV shows the toxicities associated with TC chemotherapy. Myelosuppression was the most common toxicity. Grade $\geq 3$ neutropenia occurred in 10 patients $(62.5 \%)$, while febrile neutropenia was only observed in 1 patient $(6.3 \%)$; no patients showed severe infection.

Grade 3 anemia developed in 2 patients $(12.5 \%)$ and grade 3 thrombocytopenia developed in 2 patients $(12.5 \%)$. With regard to non-hematological toxicities, grade 3 neuropathy and grade 3 anorexia developed in 1 patient each. All other toxicities were less than grade 3 . There were no treatment-related deaths among the 16 patients.
Table III. The analysis of the responses of patients who received TC chemotherapy.

\begin{tabular}{lcc}
\hline Response & $\begin{array}{c}\text { No. of } \\
\text { patients }\end{array}$ & $\begin{array}{c}\text { Response } \\
\text { rate }(\%)\end{array}$ \\
\hline CR & 1 & 6.2 \\
PR & 2 & 12.5 \\
SD & 6 & 37.5 \\
PD & 7 & 43.8 \\
Overall response rate (CR + PR) & 3 & 18.7 \\
Disease contorl rate (CR + PR + SD) & 9 & 56.2 \\
\hline
\end{tabular}

TC, paclitaxel and carboplatin; CR, complete response; PR, partial response; $\mathrm{SD}$, stable disease; $\mathrm{PD}$, progressive disease.

\section{Discussion}

Cisplatin-based systemic chemotherapy is the gold standard approach for the treatment of advanced or metastatic UC. Recently, GC chemotherapy has become the standard first-line treatment for advanced and metastatic UC because GC chemotherapy showed equivalent efficacy and lower toxicity in comparison to MVAC chemotherapy $(8,15)$. However, long-term follow-up has revealed that the rates of overall survival and progression-free survival are poor, particularly in patients with metastatic UC $(7,15)$. In addition, the data were insufficient to recommend TC as standard second-line chemotherapy after the failure of cisplatin-based combination chemotherapy (particularly GC). Thus, we retrospectively assessed the outcomes and toxicities of patients with metastatic or advanced UC after the failure of GC chemotherapy who selected to receive MVAC or TC as second-line chemotherapy in comparison to those who received the BSC.

Various single agents and combinations of agents have been reported as second-line chemotherapy regimens (16-23). Even in the NCCN guidelines, the second-line chemotherapy data are highly variable and unclear in this setting; thus, no standard therapy exists. The NCCN bladder cancer panel members highly recommend the performance of a clinical trial (24). In our institution, MVAC regimen was first selected as a second-line chemotherapy regimen after the failure of GC chemotherapy. The reason for this was that MVAC was the standard first-line chemotherapy before the GC regimen was introduced. Thus, we were used to controlling the side effects. However, this study also showed that the outcomes of second-line OS were not necessarily satisfactory (Fig. 1). Thus, we employed the TC regimen (paclitaxel in combination with carboplatin) as second-line chemotherapy from April 2014.

Paclitaxel is an antimitotic spindle drug that promotes microtubular aggregation and interferes with certain cell functions, including cell mitosis, transport and motility. Single-agent paclitaxel was shown to have an overall response rate of $42 \%$ in previously untreated patients with UC (25), and 70\% when administered in combination with cisplatin (26). On the other hand, platinum-based agents have been frequently included in salvage chemotherapy, which is provided even after the failure 
Table IV. Toxicities in patients treated with TC chemotherapy.

\begin{tabular}{|c|c|c|c|c|c|}
\hline Adverse events & Grade 1 & Grade 2 & Grade 3 & Grade 4 & $\geq$ Grade $3(\%)$ \\
\hline Neutropenia & 0 & 1 & 5 & 5 & 62.5 \\
\hline Anemia & 1 & 2 & 2 & 0 & 12.5 \\
\hline Thrombocytopenia & 0 & 1 & 2 & 0 & 12.5 \\
\hline Febrile neutropenia & - & - & 1 & 0 & 6.3 \\
\hline Neuropathy & 3 & 1 & 1 & 0 & 6.3 \\
\hline Muscle pain & 0 & 2 & - & - & - \\
\hline Nausea, vomiting & 1 & 0 & 0 & 0 & 0 \\
\hline Anorexia & 5 & 3 & 1 & 0 & 6.3 \\
\hline Malaise & 6 & 4 & - & - & 0 \\
\hline Alopecia & 3 & 7 & - & - & - \\
\hline Increased creatinine & 7 & 0 & 0 & 0 & 0 \\
\hline Liver dysfunction & 0 & 0 & 0 & 0 & 0 \\
\hline
\end{tabular}

of a platinum-based regimen, and the activity of this agent against platinum-resistant disease has been reported (10-12,27). However, patients with UC often have an impaired renal function due to advanced age, prior platinum-containing chemotherapy, prior nephrectomy and/or disease-related hydronephrosis. Carboplatin is a less nephrotoxic and emetogenic platinum compound than cisplatin (28); thus, carboplatin is considered to be a favorable agent for second-line regimens.

We first assessed the OS according to the second-line treatment (Fig. 1). All the patients received GC as first-line chemotherapy for urothelial carcinoma and selected BSC or second-line chemotherapy after the failure of GC chemotherapy. The second-line treatments included BSC $(n=28$; $53.8 \%$ ) and second-line chemotherapy [ $\mathrm{n}=24 ; 46.2 \%$ (MVAC, $\mathrm{n}=8 ; \mathrm{TC}, \mathrm{n}=16)$ ] (Table I). The median OS of the patients who received $\mathrm{BSC}, \mathrm{MVAC}$ and $\mathrm{TC}$ was $2.8,5.4$ and 12.7 months, respectively. The difference between $\mathrm{BSC}$ and MVAC was not statistically significant (log-rank test, $\mathrm{P}=0.596)$. However, the difference between BSC and TC was statistically significant after Bonferroni correction $(\mathrm{P}=0.002)$. Although this study was retrospective in nature and did not formally evaluate the quality of life (QOL), the median OS of patients who received TC was longer than that of the patients who received BSC or MVAC. Thus, from the viewpoint of OS, it is possible that TC should be recommended as a second-line chemotherapy regimen, rather than MVAC, when patients indicate a desire to receive second-line chemotherapy, not BSC.

Subsequently, we performed univariate and multivariate analyses using the Cox proportional hazards model to investigate the relationship between the OS and the clinical parameters after the failure of GC chemotherapy (Table II). Univariate analyses for various factors revealed that prior nephrectomy, ECOG-PS, NLR, albumin, CRP, visceral metastases and second-line treatment were prognostic variables. Furthermore, the multivariate analyses revealed that anemia (HR 7.047, 95\% CI=1.553-35.636, $\mathrm{P}=0.011$ ), the presence of visceral metastasis (HR 4.174, 95\% CI=1.506-13.429, $\mathrm{P}=0.005$ ) and second-line treatment (TC regimen: HR 0.296 , $95 \% \mathrm{CI}=0.124-0.636, \mathrm{P}=0.003$ ) were independent prognostic factors. Several studies have examined the various prognostic factors of patients. Buti et al identified nine studies (29-37) that aimed at evaluate the prognostic factors of 1,273 patients in a second-line treatment setting. In most studies, PS, Hb, and visceral metastasis were identified as the main independent prognostic factors for OS (38). These descriptions are consistent with our observations in the present study. However, PS was not a significant factor in this study. One reason was that second-line chemotherapy was administered (especially TC) even to patients with a relatively poor PS, because this regimen was well tolerated and could be safely used (Table IV). The other reason was that this study included patients who chose $\mathrm{BSC}$, despite having a relatively good PS, due to the fact that second-line chemotherapy represented a palliative-rather than curative-treatment. In addition, second-line chemotherapy with TC but not MVAC, was an independent prognostic factor in this study (TC: HR 0.296, 95\% CI=0.124-0.636, $\mathrm{P}=0.003$ ).

Thus, we assessed the outcome and toxicities of TC. This study demonstrated that TC was associated with an $18.7 \%$ overall response rate and a $56.2 \%$ disease control rate (Table III). The toxicities that occurred in association with TC are shown in Table IV. Myelosuppression was the most common grade $\geq 3$ toxicity. Grade $\geq 3$ neutropenia occurred in 10 patients $(62.5 \%)$ and was easily managed with G-CSF. Febrile neutropenia was only observed in 1 patient $(6.3 \%)$; however, there were no cases of severe infection. Although grade 3 anemia occurred in 2 patients $(12.5 \%)$ and grade 3 thrombocytopenia occurred in 2 patients $(12.5 \%)$, transfusion was not required in any of these cases. However, with regard to non-hematological toxicity, grade 3 neuropathy and grade 3 anorexia occurred in 1 patient each. The other toxicities were less than grade 3 and no cases of treatment-related death occurred among the 16 patients. These findings suggest that the TC could be safely administered, even after intensive treatment with GC as a first-line regimen. There are some articles which have previously reported the efficacy and tolerability of TC as second-line chemotherapy for advanced UC resistant to first-line cisplatin-based chemotherapy in Japanese patients $(11,39)$. However, these studies did not compare the outcomes of TC with the outcomes of other treatments, including MVAC and BSC. 
Recently, immune checkpoint inhibitors such as anti-programmed cell death 1 and anti-programmed cell death-ligand 1 (PD-L1) antibodies have been reported to have durable effects in various cancers $(40,41)$. Thomas et al reported that anti-PD-L1 antibody treatment was effective for patients with metastatic bladder cancer, and reported that the ORR was $25 \%$ and that severe adverse events were rare (42). In the future, studies should be performed to compare anti-PD-L1 antibody therapy and chemotherapy as second-line treatment for metastatic UC.

The present study is associated with some limitations. First, the data related to the efficacy and tolerability of TC as second-line chemotherapy were evaluated retrospectively, and not in a randomized trial. Second, the study population was relatively small. Further studies will be needed to confirm our data in a larger study population. Although our analysis relied on a small sample study population, TC achieved a $56.2 \%$ disease control rate with a tolerable toxicity profile as second-line chemotherapy in patients with advanced or metastatic UC who have previously received GC as first-line chemotherapy. Although this study did not formally evaluate the QOL, the median OS of the patients who received TC was longer than that of the patients who received BSC or MVAC (12.7 vs. 2.8 months or 5.4 months, respectively). Additionally, TC chemotherapy was itself a prognostic factor in the multivariate analysis. Taken together the results suggest that at present, when there is no standard second-line treatment for patients with advanced or metastatic UC after failure of GC chemotherapy, TC chemotherapy can be a preferred option for second-line chemotherapy.

\section{References}

1. Vaidya A, Soloway MS, Hawke C, Tiguert R and Civantos F: De novo muscle invasive bladder cancer: Is there a change in trend? J Urol 165: 47-50, 2001.

2. Stein JP, Lieskovsky G, Cote R, Groshen S, Feng AC, Boyd S, Skinner E, Bochner B, Thangathurai D, Mikhail M, et al: Radical cystectomy in the treatment of invasive bladder cancer: Long-term results in 1,054 patients. J Clin Oncol 19: 666-675, 2001 .

3. Sternberg CN, Yagoda A, Scher HI, Watson RC, Ahmed T, Weiselberg LR, Geller N, Hollander PS, Herr HW, Sogani PC, et al: Preliminary results of M-VAC (methotrexate, vinblastine, doxorubicin and cisplatin) for transitional cell carcinoma of the urothelium. J Urol 133: 403-407, 1985.

4. Loehrer PJ Sr, Einhorn LH, Elson PJ, Crawford ED, Kuebler P, Tannock I, Raghavan D, Stuart-Harris R, Sarosdy MF, Lowe BA, et al: A randomized comparison of cisplatin alone or in combination with methotrexate, vinblastine and doxorubicin in patients with metastatic urothelial carcinoma: A cooperative group study. J Clin Oncol 10: 1066-1073, 1992.

5. Sternberg CN, Yagoda A, Scher HI, Watson RC, Geller N, Herr HW, Morse MJ, Sogani PC, Vaughan ED, Bander N, et al: Methotrexate, vinblastine, doxorubicin, and cisplatin for advanced transitional cell carcinoma of the urothelium. Efficacy and patterns of response and relapse. Cancer 64: 2448-2458, 1989.

6. Sternberg CN, Yagoda A, Scher HI, Watson RC, Herr HW, Morse MJ, Sogani PC, Vaughan ED Jr, Bander N, Weiselberg LR, et al: M-VAC (methotrexate, vinblastine, doxorubicin and cisplatin) for advanced transitional cell carcinoma of the urothelium. J Urol 139: 461-469, 1988.

7. Saxman SB, Propert KJ, Einhorn LH, Crawford ED, Tannock I, Raghavan D, Loehrer PJ Sr and Trump D: Long-term follow-up of a phase III intergroup study of cisplatin alone or in combination with methotrexate, vinblastine, and doxorubicin in patients with metastatic urothelial carcinoma: A cooperative group study. J Clin Oncol 15: 2564-2569, 1997.
8. von der Maase H, Hansen SW, Roberts JT, Dogliotti L, Oliver T, Moore MJ, Bodrogi I, Albers P, Knuth A, Lippert CM, et al: Gemcitabine and cisplatin versus methotrexate, vinblastine, doxorubicin, and cisplatin in advanced or metastatic bladder cancer: Results of a large, randomized, multinational, multicenter, phase III study. J Clin Oncol 18: 3068-3077, 2000.

9. Bellmunt J, Théodore C, Demkov T, Komyakov B, Sengelov L, Daugaard G, Caty A, Carles J, Jagiello-Gruszfeld A, Karyakin O, et al: Phase III trial of vinflunine plus best supportive care compared with best supportive care alone after a platinum-containing regimen in patients with advanced transitional cell carcinoma of the urothelial tract. J Clin Oncol 27: 4454-4461, 2009.

10. Vaishampayan UN, Faulkner JR, Small EJ, Redman BG, Keiser WL, Petrylak DP and Crawford ED: Phase II trial of carboplatin and paclitaxel in cisplatin-pretreated advanced transitional cell carcinoma: A Southwest Oncology Group study. Cancer 104: 1627-1632, 2005.

11. Soga N, Onishi T, Arima K and Sugimura Y: Paclitaxel Carboplatin chemotherapy as a second-line chemotherapy for advanced platinum resistant urothelial cancer in Japanese cases. Int J Urol 14: 828-832, 2007.

12. Kouno T, Ando M, Yonemori K, Matsumoto K, Shimizu C, Katsumata N, Komiyama M, Okajima E, Matsuoka N, Fujimoto $\mathrm{H}$ and Fujiwara Y: Weekly paclitaxel and carboplatin against advanced transitional cell cancer after failure of a platinum-based regimen. Eur Urol 52: 1115-1122, 2007.

13. http://ctep.cancer.gov/protocolDevelopment/electronic_applications/ctc.htm\#ctc 40 .

14. Eisenhauer EA, Therasse P, Bogaerts J, Schwartz LH, Sargent D, Ford R, Dancey J, Arbuck S, Gwyther S, Mooney M, et al: New response evaluation criteria in solid tumours: Revised RECIST guideline (version 1.1). Eur J Cancer 45: 228-247, 2009.

15. von der Maase H, Sengelov L, Roberts JT, Ricci S, Dogliotti L, Oliver T, Moore MJ, Zimmermann A and Arning M: Long-term survival results of a randomized trial comparing gemcitabine plus cisplatin, with methotrexate, vinblastine, doxorubicin, plus cisplatin in patients with bladder cancer. J Clin Oncol 23: 4602-4608, 2005.

16. Lorusso V, Pollera CF, Antimi M, Luporini G, Gridelli C, Frassineti GL, Oliva C, Pacini M and De Lena M: A phase II study of gemcitabine in patients with transitional cell carcinoma of the urinary tract previously treated with platinum. Italian Co-operative Group on Bladder Cancer. Eur J Cancer 34: 1208-1212, 1998.

17. McCaffrey JA, Hilton S, Mazumdar M, Sadan S, Kelly WK, Scher HI and Bajorin DF: Phase II trial of docetaxel in patients with advanced or metastatic transitional-cell carcinoma. J Clin Oncol 15: 1853-1857, 1997.

18. Papamichael D, Gallagher CJ, Oliver RT, Johnson PW and Waxman J: Phase II study of paclitaxel in pretreated patients with locally advanced/metastatic cancer of the bladder and ureter. $\mathrm{Br} \mathrm{J}$ Cancer 75: 606-607, 1997.

19. Vaughn DJ, Broome CM, Hussain M, Gutheil JC and Markowitz AB: Phase II trial of weekly paclitaxel in patients with previously treated advanced urothelial cancer. J Clin Oncol 20: 937-940, 2002.

20. Sweeney CJ, Roth BJ, Kabbinavar FF, Vaughn DJ, Arning M, Curiel RE, Obasaju CK, Wang Y, Nicol SJ and Kaufman DS: Phase II study of pemetrexed for second-line treatment of transitional cell cancer of the urothelium. J Clin Oncol 24: 3451-3457, 2006.

21. Galsky MD, Mironov S, Iasonos A, Scattergood J, Boyle MG and Bajorin DF: Phase II trial of pemetrexed as second-line therapy in patients with metastatic urothelial carcinoma. Invest New Drugs 25: 265-270, 2007.

22. Witte RS, Elson P, Bono B, Knop R, Richardson RR, Dreicer R and Loehrer PJ Sr: Eastern Cooperative Oncology Group phase II trial of ifosfamide in the treatment of previously treated advanced urothelial carcinoma. J Clin Oncol 15: 589-593, 1997.

23. Han KS, Joung JY, Kim TS, Jeong IG, Seo HK, Chung J and Lee KH: Methotrexate, vinblastine, doxorubicin and cisplatin combination regimen as salvage chemotherapy for patients with advanced or metastatic transitional cell carcinoma after failure of gemcitabine and cisplatin chemotherapy. Br J Cancer 98: 86-90, 2008.

24. National Comprehensive Cancer Network: Guidelines on bladder cancer. https://www.nccn.org/professionals/physician gls/pdf/bladder.pdf/. Accessed December 1, 2016. 
25. Roth BJ, Dreicer R, Einhorn LH, Neuberg D, Johnson DH, Smith JL, Hudes GR, Schultz SM and Loehrer PJ: Significant activity of paclitaxel in advanced transitional-cell carcinoma of the urothelium: A phase II trial of the Eastern Cooperative Oncology Group. J Clin Oncol 12: 2264-2270, 1994.

26. Burch PA, Richardson RL, Cha SS, Sargent DJ, Pitot HC IV, Kaur JS and Camoriano JK: Phase II study of paclitaxel and cisplatin for advanced urothelial cancer. J Urol 164: 1538-1542, 2000.

27. Pagliaro LC, Millikan RE, Tu SM, Williams D, Daliani D, Papandreou CN and Logothetis CJ: Cisplatin, gemcitabine and ifosfamide as weekly therapy: A feasibility and phase II study of salvage treatment for advanced transitional-cell carcinoma. J Clin Oncol 20: 2965-2970, 2002.

28. Esteban-Fernández D, Verdaguer JM, Ramírez-Camacho R, Palacios MA and Gómez-Gómez MM: Accumulation, fractionation and analysis of platinum in toxicologically affected tissues after cisplatin, oxaliplatin and carboplatin administration. J Anal Toxicol 32: 140-146, 2008

29. Albers P, Park SI, Niegisch G, Fechner G, Steiner U, Lehmann J, Heimbach D, Heidenreich A, Fimmers R and Siener R; AUO Bladder Cancer Group: Randomized phase III trial of 2nd line gemcitabine and paclitaxel chemotherapy in patients with advanced bladder cancer: Short-term versus prolonged treatment [German Association of Urological Oncology (AUO) trial AB 20/99]. Ann Oncol 22: 288-294, 2011.

30. Pond GR, Bellmunt J, Fougeray R, Choueiri TK, Qu AQ Niegisch G, Albers P, Di Lorenzo G, Salhi Y, Galsky MD, et al: Impact of response to prior chemotherapy in patients with advanced urothelial carcinoma receiving second-line therapy: Implications for trial design. Clin Genitourin Cancer 11: 495-500, 2013.

31. Bellmunt J, Choueiri TK, Fougeray R, Schutz FA, Salhi Y, Winquist E, Culine S, von der Maase H, Vaughn DJ and Rosenberg JE: Prognostic factors in patients with advanced transitional cell carcinoma of the urothelial tract experiencing treatment failure with platinum-containing regimens. J Clin Oncol 28: 1850-1855, 2010.

32. Niegisch G, Fimmers R, Siener R, Park SI and Albers P; German Association of Urological Oncology Bladder Cancer Group: Prognostic factors in second-line treatment of urothelial cancers with gemcitabine and paclitaxel (German Association of Urological Oncology trial AB20/99). Eur Urol 60: 1087-1096, 2011.

33. Ikeda M, Matsumoto K, Tabata K, Minamida S, Fujita T, Satoh T, Iwamura M and Baba S: Combination of gemcitabine and paclitaxel is a favorable option for patients with advanced or metastatic urothelial carcinoma previously treated with cisplatin-based chemotherapy. Jpn J Clin Oncol 41: 1214-1220, 2011.
34. Lee JL, Ahn JH, Park SH, Lim HY, Kwon JH, Ahn S, Song C, Hong JH, Kim CS and Ahn H: Phase II study of a cremophor-free, polymeric micelle formulation of paclitaxel for patients with advanced urothelial cancer previously treated with gemcitabine and platinum. Invest New Drugs 30: 1984-1990, 2012.

35. Krajewski KM, Fougeray R, Bellmunt J, Pons F, Schutz FA, Rosenberg JE, Salhi Y and Choueiri TK: Optimisation of the size variation threshold for imaging evaluation of response in patients with platinum-refractory advanced transitional cell carcinoma of the urothelium treated with vinflunine. Eur J Cancer 48: 1495-1502, 2012

36. Choueiri TK, Ross RW, Jacobus S, Vaishampayan U, Yu EY, Quinn DI,Hahn NM, Hutson TE, Sonpavde G, Morrissey SC, et al: Double-blind, randomized trial of docetaxel plus vandetanib versus docetaxel plus placebo in platinum-pretreated metastatic urothelial cancer. J Clin Oncol 30: 507-512, 2012.

37. Ko YJ, Canil CM, Mukherjee SD, Winquist E, Elser C, Eisen A, Reaume MN, Zhang L and Sridhar SS: Nanoparticle albumin-bound paclitaxel for second-line treatment of metastatic urothelial carcinoma: A single group, multicentre, phase 2 study. Lancet Oncol 14: 769-776, 2013.

38. Buti S, Ciccarese C, Zanoni D, Santoni M, Modena A, Maines F, Gilli A, Bria E, Brunelli M, Rimanti A, et al: Prognostic and predictive factors in patients treated with chemotherapy for advanced urothelial cancer: Where do we stand? Future Oncol 11: 107-119, 2015.

39. Terakawa T, Miyake H, Yokoyama N, Miyazaki A, Tanaka H, Inoue T and Fujisawa M: Clinical outcome of paclitaxel and carboplatin as second-line chemotherapy for advanced urothelial carcinoma resistant to first-line therapy with gemcitabine and cisplatin. Urol Int 92: 180-185, 2014.

40. Weinstock $M$ and McDermott D: Targeting PD-1/PD-L1 in the treatment of metastatic renal cell carcinoma. Ther Adv Urol 7: 365-377, 2015.

41. Hamid O, Robert C, Daud A, Hodi FS, Hwu WJ, Kefford R, Wolchok JD, Hersey P, Joseph RW, Weber JS, et al: Safety and tumor responses with lambrolizumab (anti-PD-1) in melanoma. N Engl J Med 369: 134-144, 2013.

42. Powles T, Eder JP, Fine GD, Braiteh FS, Loriot Y, Cruz C, Bellmunt J, Burris HA, Petrylak DP, Teng SL, et al: MPDL3280A (anti-PD-L1) treatment leads to clinical activity in metastatic bladder cancer. Nature 515: 558-562, 2014. 